\title{
WAVE REFLECTION FROM COMPOSITE SLOPES
}

\author{
Barbara Zanuttigh $^{1}$ and Jentsje W. van der Meer ${ }^{2}$
}

\begin{abstract}
This paper analyses wave reflection from composite slopes by means of an extensive database, which includes smooth and rock (permeable and impermeable core) slopes and slopes with all kind of artificial armour units. The aim of this research was to identify the proper evaluation of the breaker parameter so that the formula the Authors already developed for straight slopes could be applied also to structures with berms, toes and in general to composite slopes. The correct evaluation of the breaker parameter is focused on a more accurate estimation of the structure slope. Based on the observation that for reflection, differently from what happens for overtopping and runup, the whole slope below m.sl. is really important, the slope to appear in the breaker parameter is evaluated as a weighted average of the partial slopes and it is included in the proposed prediction formula, obtaining a good agreement with the original database for straight slopes.
\end{abstract}

\section{INTRODUCTION}

The problems associated with reflection of incoming waves from coastal structures and natural coasts are well recognized and include dangerous sea states close to harbors entrances, influence on ship navigation in entrance channels and intensified sediment scour, which can lead to dramatic loss in beach material and structure destabilization. Moreover, numerical models for the calculation of wave penetration need a good estimation of the reflection coefficients $K_{r}$ for all kind of structures. Due to the adverse effects of wave reflection, coastal engineers require design criteria which enable cost effective structures to be built with acceptable reflection performances.

Research dedicated to wave reflection from coastal structures only is fairly limited and mainly dedicated to the assessment of $K_{r}$. For smooth impermeable slopes, Miche (1951) empirically determined $K_{r}$ for monochromatic waves breaking on a plane beach. Battjes (1974) redefined Miche's hypothesis in terms of the Iribarren number or breaker parameter $\xi$. Ursell et al. (1960) and Seelig and Ahrens (1981) indicated that Miche's equation significantly overestimated the reflection of both regular and irregular waves and presented an improved estimate of $K_{r}$.

For rough permeable slopes, Numata (1976) suggested an empirical equation for $K_{r}$ based on the breakwater width to armour diameter ratio. Losada and Gimenez-Curto (1981) developed an exponential model for $K_{r}$ based on $\xi$; Seelig and Ahrens (1981) postulated that wave reflection from porous structures is also a function of the toe depth, the offshore seabed slope, the armour characteristic and the number of armour layers. Postma (1989) analysis revealed a strong dependence of $K_{r}$ on $\xi$ and negligible correlations with spectral form and toe depth. Van der Meer (1992) improved Postma's analysis through a

\footnotetext{
1 DISTART Idraulica, University of Bologna, Viale Risorgimento 2, 40136 Bologna, Italy, barbara.zanuttigh@unibo.it

2 Van der Meer Consulting b. v., Voorsterweg 28, 8316 PT, Marknesse, The Netherlands, jm@vandermeerconsulting.nl
} 
multiple regression method to separate the effects of wave height and period, structure permeability and slope. Davidson et al. (1996) developed a new prediction scheme based on the identification of a non-dimensional parameter that weights the contributions of wave length, wave height, toe water depth, structure slope and armour diameter.

For tetrapods, sheds and diodes, Allsop and Hettiarachchi (1989) provided proper values for the two coefficients in Seelig and Ahrens (1981) formula.

All the formulae with the exception of Numata (1976), Van der Meer (1992) and Davidson et al. (1996), relate $K_{r}$ to $\xi$ only and adopt for $\xi$ the peak wave period at the structure toe $\xi_{o p}$ with the exception of Allsop and Hiettrarchi (1989) who use the mean wave period.

The EU-projects DELOS (on wave transmission) and CLASH (on wave overtopping) generated large sets of tests on all kind of structures, where for large parts of the data sets the reflection coefficient $K_{r}$ is available.

The reflection behaviour for various type of straight slopes has been analysed in depth by Zanuttigh and Van der Meer (2006), providing a new prediction formula validated for design conditions.

The objectives of this paper are:

- to develop a formula for the prediction of $K_{r}$ in presence of straight and composite slopes for all kind of material, under perpendicular wave attack;

- based on the already developed formula for straight slopes, to identify parameters to modify the evaluation of the breaker parameter for composite slopes and berms.

To achieve these objectives, two methodologies have been adopted:

- the analysis of reflection for structures with berms, composite slopes, toe protections through the reflection database (Zanuttigh and Van der Meer, 2006);

- numerical simulations with the 2DV COBRAS code developed by the Cornell University and by the University of Cantabria (see for instance Garcia et al., 2004), which are still in progress but helped a lot in the reconstruction of the physical processes.

\section{THE REFLECTION DATABASE AND THE NEW FORMULA}

Zanuttigh and Van der Meer (2006) prepared a wide reflection database, which includes part of the DELOS wave transmission database (Van der Meer et al., 2005), part of the CLASH wave overtopping database (general presentation in Steendam et al, 2004; armour unit data in Bruce et al., 2006), data acquired from model testing in European facilities, field measurements (at Elmer, UK, see Davidson et al., 1996), recent tests on low crested structures (Cappietti et al., 2006), for a total of about 6000 data. The format of the reflection database is the same as the homogeneous database of CLASH (see below), where all kind of coastal structures (slopes, vertical, smooth, rough, combinations, etc.) have been described by structure parameters. 
Based on results from CLASH, the wave period adopted is the spectral period at the structure toe

$$
\xi_{o}=\frac{\tan \alpha}{\sqrt{\left(2 \pi H_{m 0 t}\right) /\left(g T_{m-1,0}^{2}\right)}}
$$

where $T_{m-1,0}=m_{-1} / m_{0}$. The parameter $\xi_{o}$ is useful for representing bi-modal spectra or shallow water with flat spectra. For single-peak spectra, $T_{m-1,0}=T_{p} / 1.1$. From the work by Postma (1989) it is known that the wave period has more influence than the wave height on the reflection behaviour, so the use of $\xi_{o}$ introduces some scatter, but it also allows to incorporate different slopes.

The analysis was restricted to straight slopes under perpendicular wave attack in design conditions (defined as: $R_{c} / H_{m 0 t} \geq 0.5, H_{m 0 t} / D_{n 50} \geq 1.0, s_{o} \geq 0.01$, where $R_{c}$ is the structure freeboard, $H_{m 0 t}$ is the significant incident wave height at the toe of the structure, $D_{n 50}$ is the nominal structure diameter, $s_{o}$ is wave steepness based on $T_{m-1,0}$ ), for a total of about 600 data.

The steps of the analysis were the following. Different empirical formulae were compared with available data, but with the exception of Seelig and Ahrens (1981) for smooth slopes, other formulae for rocks and armour units show quite a lot of scatter.

The basic idea was to have just one formula that can be adapted to all data by simply changing coefficients. The first try was done by refitting Seelig and Ahrens (1981) formula on rocks with permeable and impermeable core, but this did not give satisfactory results.

A new formula was thus developed:

- for all data types,

- representing physical bounds,

- validated for straight slopes in design conditions (but an extension of the formula to low crested structures was also provided),

- $\quad$ depending on the roughness factor $\gamma_{f}$ (TAW, 2002; Bruce et al., 2006; EurOtop Manual, 2007), a requirement that strictly relates overtopping and reflection performance and that we will explain more in details below.

The new formula is given by

$$
K_{r}=\tanh \left(a \cdot \xi_{o}^{b}\right)
$$

where the calibrated values of the coefficients $a$ and $b$ are reported in Table 1 . This formula and these values for $a$ and $b$ have been obtained by analyzing average values of $K_{r}$ by groups of $\xi_{\mathrm{o}}$. The agreement among straight slopes (around 600 data) and Eq. (2) is shown in Figure 1.

Reflection and overtopping performance of coastal structures are strongly related: large roughness and permeability give low overtopping and low reflection, due to more dissipation; and visa versa, smooth slopes give more overtopping and higher reflection. 
It has been shown that the coefficients $a$ and $b$ in Eq. (2) directly depend on the roughness factor $\gamma_{f}$. By fitting the three values we have for $a, b$ and $\gamma_{f}$ (Table 1 ; rock permeable, rock impermeable and smooth slopes) the following expressions for $a$ and $b$ were derived

$$
a=0.167 \cdot\left[1-\exp \left(-3.2 \cdot \gamma_{f}\right)\right], b=1.49 \cdot\left(\gamma_{f}-0.38\right)^{2}+0.86
$$

Since $\gamma_{f}$ has been measured or determined for a lot of materials or structures roughness (TAW, 2002; Bruce et al., 2006), the dependence of $a$ and $b$ on this parameter allows to straightforward extend the new reflection formula to a wide variety of slopes with different roughness, obtaining good predictions without any refitting (see the results reported in Zanuttigh and van der Meer, 2006).

\begin{tabular}{|l|l|l|l|}
\hline \multicolumn{3}{|c|}{ Table 1. Coefficients $\boldsymbol{a}, \boldsymbol{b}$ to be included in Eq. (2). } \\
\hline & $a$ & $b$ & $\gamma_{f}$ \\
\hline Rock permeable & 0.12 & 0.87 & 0.40 \\
Armour units & 0.12 & 0.87 & Various \\
Rock impermeable & 0.14 & 0.90 & 0.55 \\
Smooth & 0.16 & 1.43 & 1.00 \\
\hline
\end{tabular}

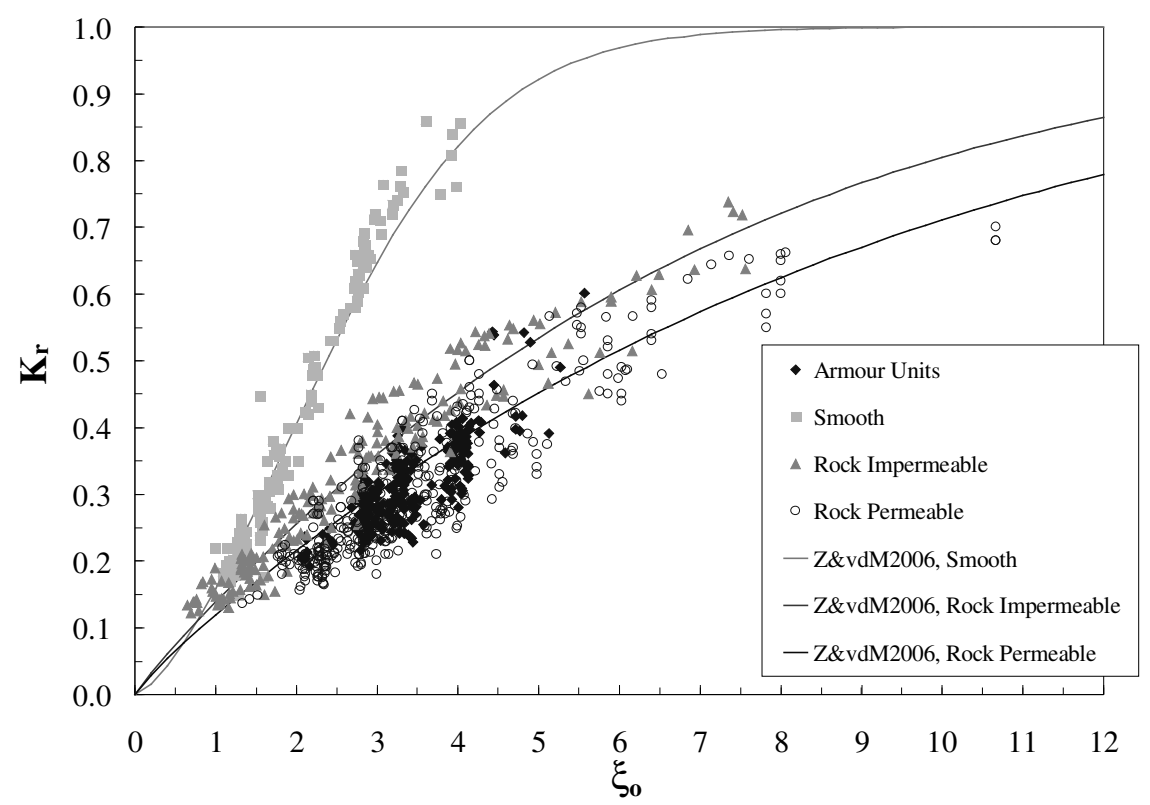

Figure 1. Data for straight slopes and Eq. (2), represented by lines, with coefficients reported in Table 1. 


\section{REFLECTION FOR STRUCTURES WITH COMPOSITE SLOPES}

The structures in the reflection database are schematized as in the CLASH overtopping database (Fig. 2), where four different structure slopes are included based on the observation that for overtopping the most relevant processes occur in the rundown and run-up area (defined as $\pm 1.5 H_{\mathrm{mot}}$ with respect to still water level, swL):

- the downstream slope $\alpha_{\mathrm{d}}$, which is the structure slope below the run-up;

- the average structure slope around swL $\alpha_{\text {incl }}$ which includes a possible berm;

- the berm slope $\alpha_{\mathrm{b}}$ with respect to the horizontal;

- the upstream structure slope above the rundown area $\alpha_{u}$.

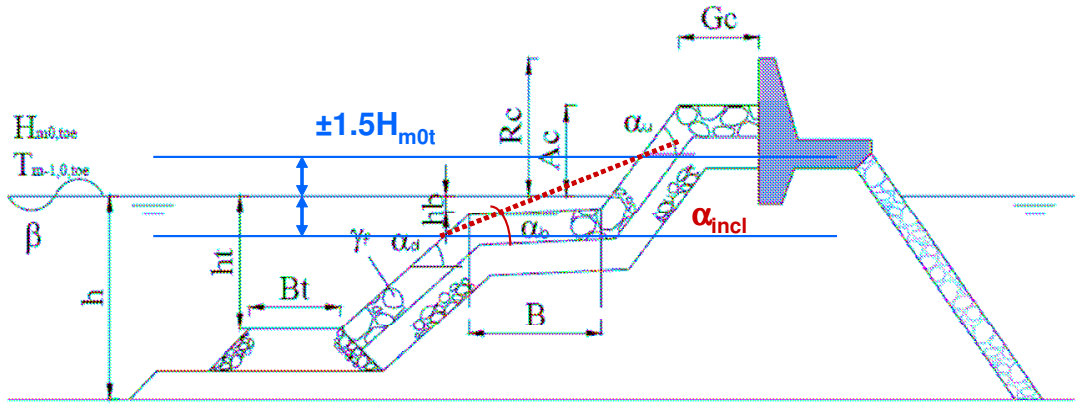

Figure 2. Structure parameters in the reflection database, based on CLASH. Scheme redrawn from van Gent et al. (2007).

Few information on wave reflection from composite slopes is available in the literature; Andersen (2006) found in his tests on berm breakwaters that the breaker parameter can be calculated as:

$$
\xi_{o}=\frac{\tan \alpha_{i n c l}}{\sqrt{H_{m 0 t} / L_{0}}}
$$

Based on our analysis of the experimental database and of the numerical simulations, for reflection it is relevant to consider the whole slope below swL. This slope can be represented by the average slope $\alpha_{\text {incl }}$ only when the water depth at the toe $h$ is sufficiently shallow, whereas in case of deeper conditions we suggest to use a weighted average of the structure slopes:

$$
\begin{aligned}
& \xi_{o}=\frac{\left[\tan \alpha_{d} \cdot\left(h-1.5 H_{m 0 t}\right)+\tan \alpha_{i n c} \cdot 1.5 H_{m 0 t}\right] / h}{\sqrt{H_{m 0 t} / L_{0}}} \text { if } h>1.5 H_{m 0 t} \\
& \xi_{o}=\frac{\tan \alpha_{i n c l}}{\sqrt{H_{m 0 t} / L_{0}}} \text { if } h \leq 1.5 H_{m 0 t}
\end{aligned}
$$



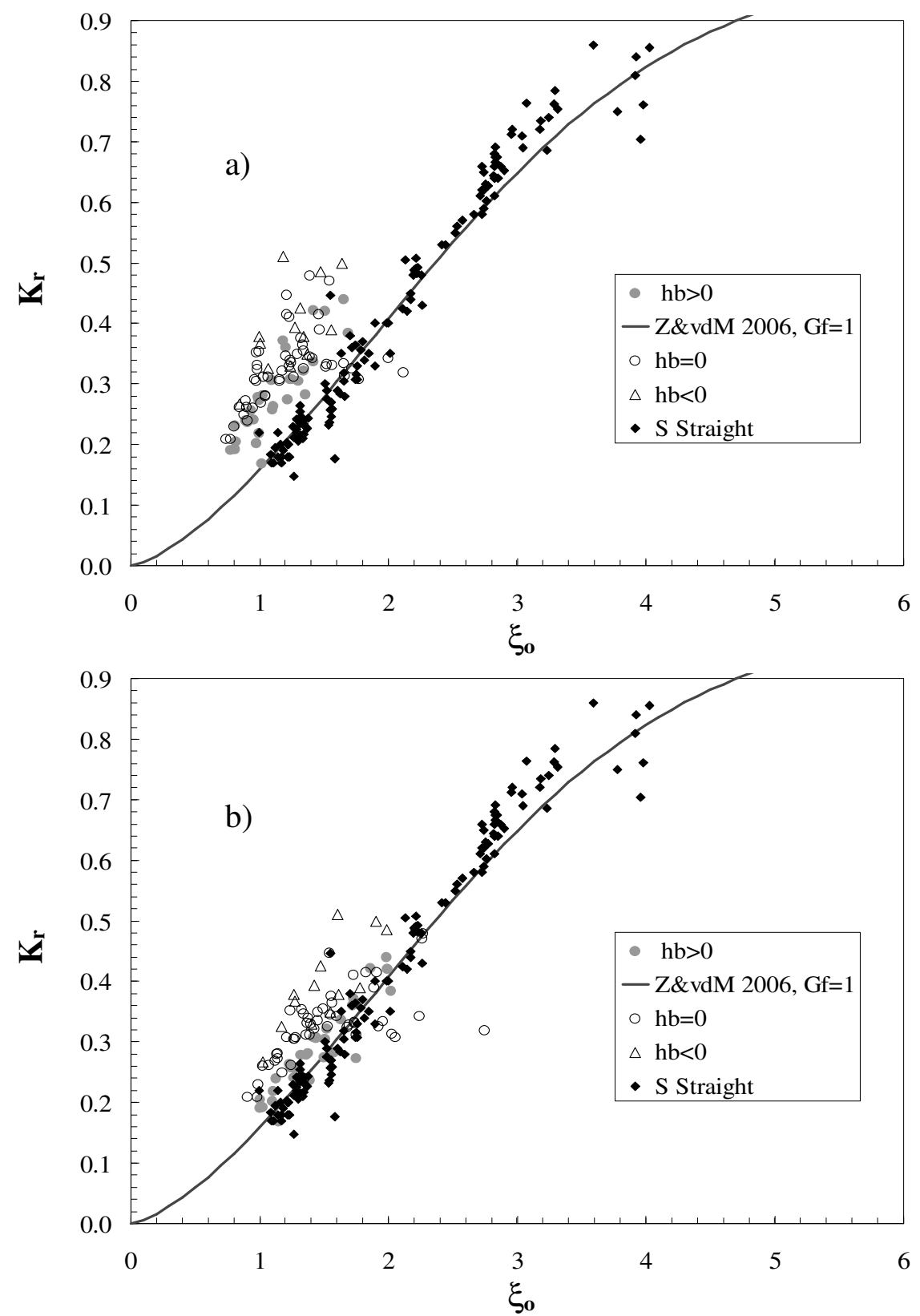

Figure 3. Comparison of data for a sample case with a smooth structure and a flat berm. The breaker parameter is evaluated: a) following Eq. (4); b) following Eq. (5). Black diamonds are all the smooth data from the straight slope database. The black line represents Eq. (2). The berm position with respect to swL is indicated by $h_{b}$ (submerged when positive). 

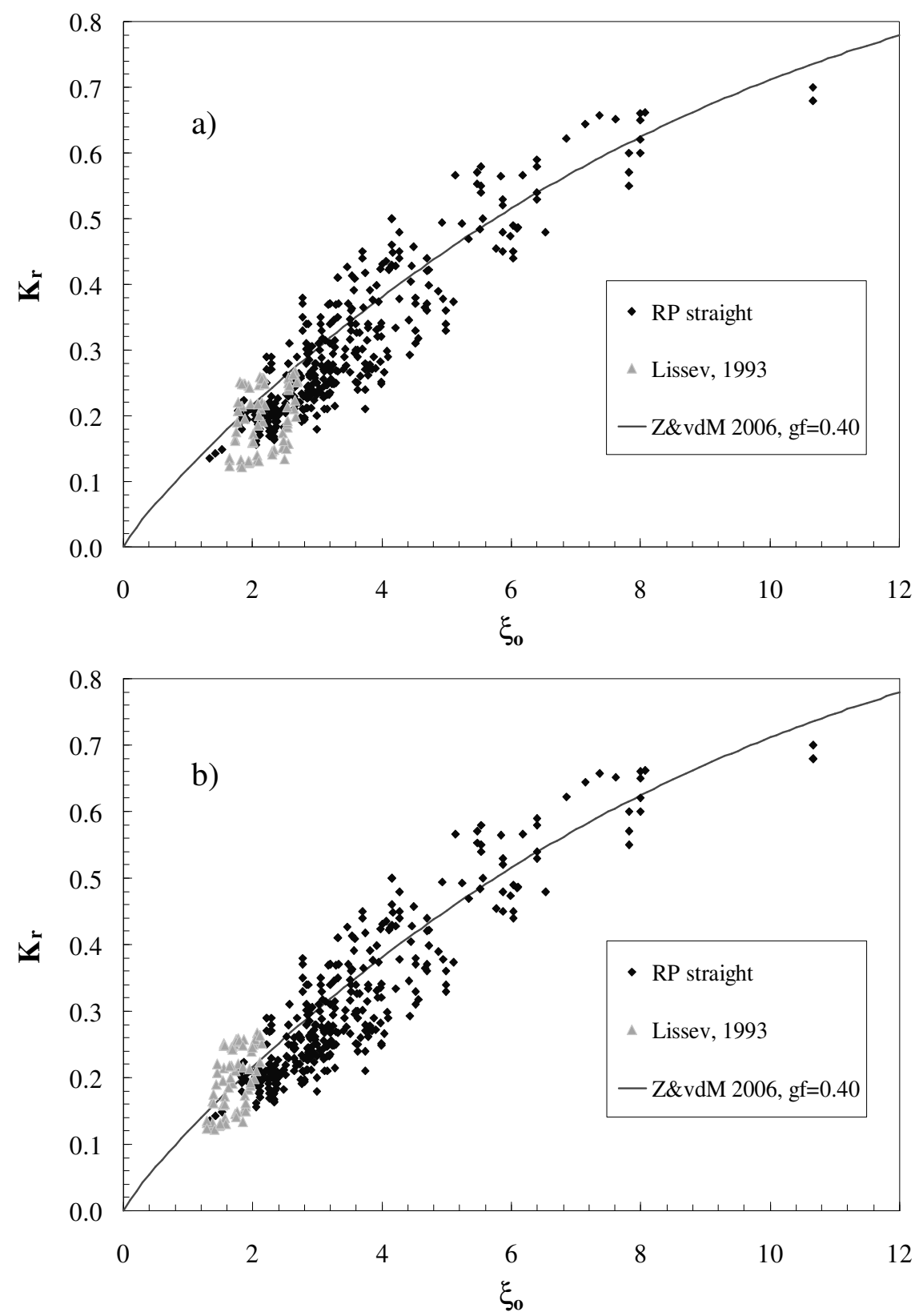

Figure 4. Comparison of data for a sample case with a rock permeable berm breakwater with submerged berm (Lissev, 1993). The breaker parameter is evaluated: a) following Eq. (4); b) following Eq. (5). Black diamonds are all the rock permeable data from the straight slope database. The black line represents Eq. (2). 
Figure 3 shows the results for a sample case, a smooth structure with emerged, submerged or zero freeboard berm. If $\xi$ is evaluated following Eq. (4), all data appear too high with respect both to the formula for smooth slopes, Eq. (2), and to the original database for straight smooth slopes. By using Eq. (5) a perfect agreement is obtained in case of submerged berms, whereas emerged berms are still too high and berms at swL show still large scatter. It can thus be concluded that Eq. (5) can represent only submerged conditions and more extensive research is needed for emerged ones.

Figure 4 shows the results for another sample case, a rock permeable berm breakwater (Lissev, 1993), where the berm is always submerged and $h$ in most cases is close to $1.5 H_{\mathrm{m} 0 \mathrm{t}}$. As it is obvious by the expressions given in Eq. (5), the changes between the two data clouds obtained by Eq.s (4) and (5) are small, nevertheless the estimate of $\xi$ as in Eq. (5) allows a better agreement both with the original database for rock permeable straight slopes and with Eq. (2).

When the structure is composed by a toe and a berm, even if the toe has usually a sufficiently narrow width and low height, it appears anyway to give a contribution to the wave reflection process. This contribution can be represented again by means of a weighted average on $h$ of $\alpha_{\text {incl }}$ in the rundown area and the average structure slope below the rundown $\alpha_{\mathrm{td}}$ (Fig. 5):

$$
\begin{aligned}
& \xi_{o}=\frac{\left[\tan \alpha_{t d}\left(h-1.5 H_{m 0 t}\right)+\tan \alpha_{i n c l} 1.5 H_{m 0 t}\right] / h}{\sqrt{H_{m 0 t} / L_{0}}} \text { if } h>1.5 H_{m 0 t} \\
& \xi_{o}=\frac{\tan \alpha_{i n c l}}{\sqrt{H_{m 0 t} / L_{0}}} \text { if } h \leq 1.5 H_{m 0 t}
\end{aligned}
$$

By looking at the comparison between calculations with Eq. (4) and (6) in case of some datasets of rock permeable combined slopes, Eq. (6) allows to obtain better agreement with the database and with $\mathrm{Eq}$. (2), especially when wave attack is less intense with respect to water depth at the structure toe, as for the tests numbered as 14 and 27 within the CLASH database.

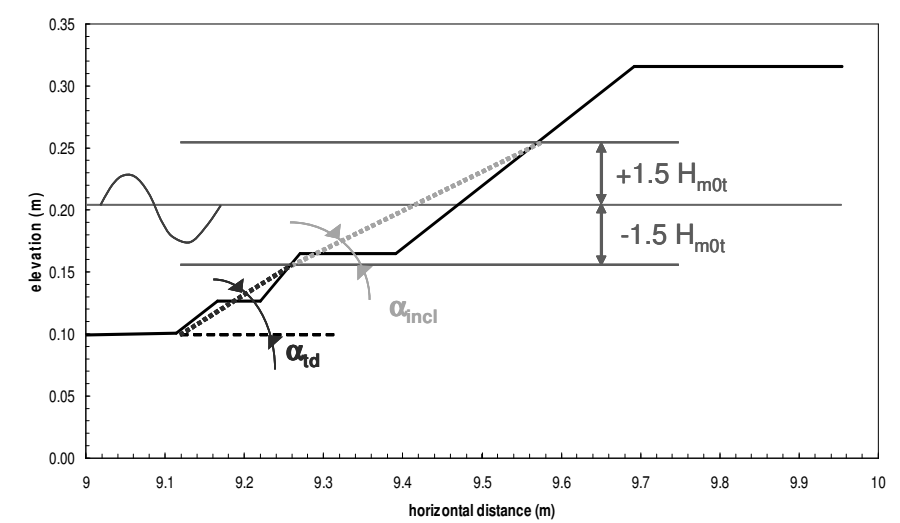

Figure 5. Structure parameters for a combined case with toe and berm. 

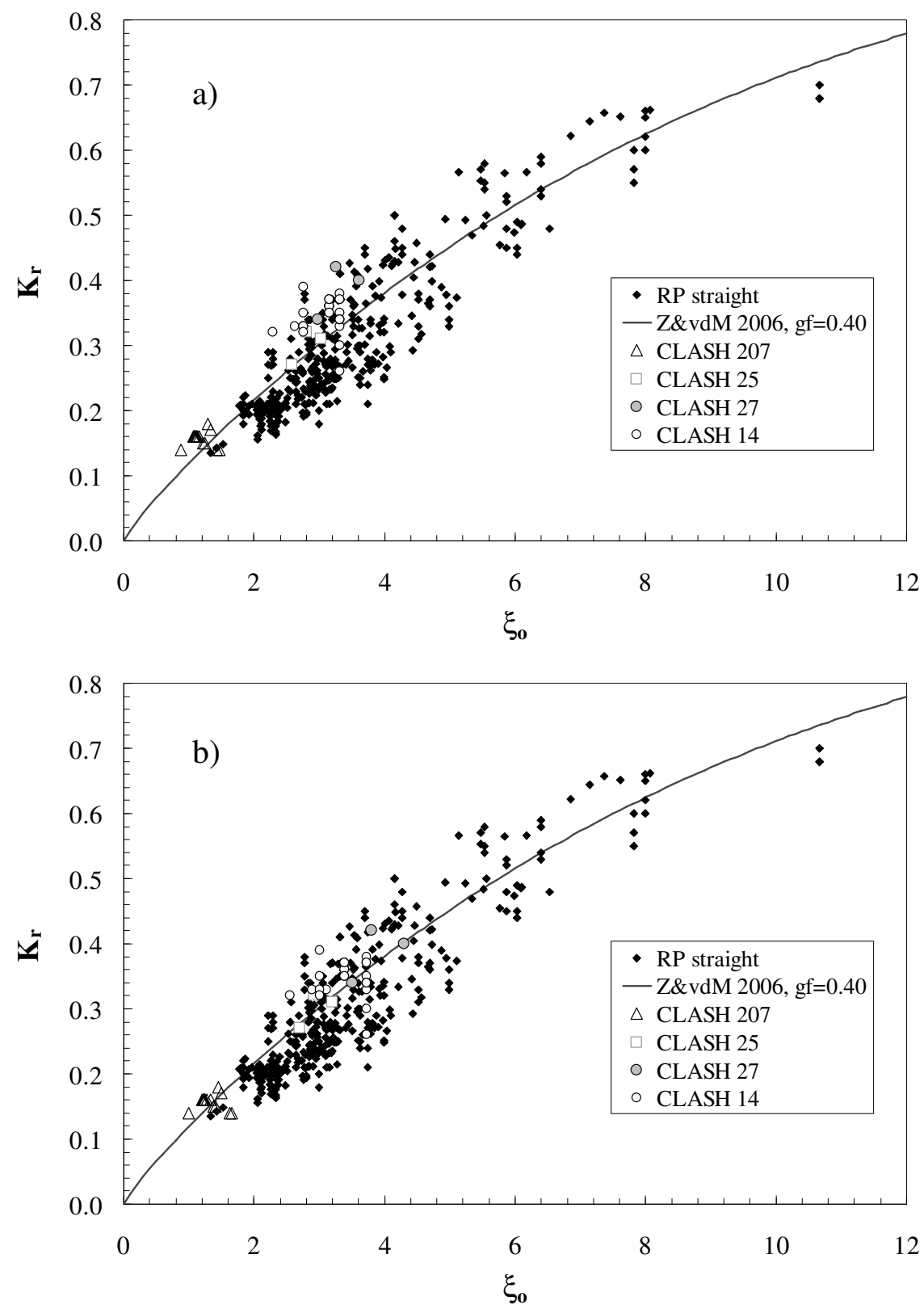

Figure 6. Comparison of data for a sample case with a rock permeable structure with toe and berm. The breaker parameter is evaluated: a) following Eq. (4); b) following Eq. (6). Black diamonds are all the rock permeable data from the straight slope database. The black line represents Eq. (2). 


\section{CONCLUSIONS}

An analysis of the breaker parameter in presence of composite slopes has been carried out to extend the formula developed by Zanuttigh and Van der Meer (2006) for straight slopes.

Differently from overtopping and run-up, for reflection it is relevant to consider the whole slope below swL, which can be calculated by a weighted average of structure slopes:

- $\quad$ in presence of a berm, between the downstream slope $\alpha_{\mathrm{d}}$ and the average slope in the run-down/up area $\alpha_{\text {incl }}$.

- $\quad$ in case of a berm and a toe, between the average slope below the rundown area, $\alpha_{\mathrm{td}}$, and the slope in the run-down/up area $\alpha_{\text {incl }}$.

When the berm is at mean swL or emerged, this kind of estimation is still too rough and further analysis is needed.

Further research will be carried out on this topic, as

- $\quad$ the systematic use of the 2D VOF numerical model

$\circ$ to check, in a more controlled environment and for a variety of sea levels and wave attacks, how the effects on reflection due to a toe, a composite slope, a berm and a wave wall are represented by the proposed parameters;

$\circ$ to get information on spectral changes induced by different seaward structure shapes;

- to analyse wave reflection with varying frequency;

- the use of a Neural Network as done in DELOS and CLASH for wave transmission and overtopping, respectively (Panizzo and Briganti, 2007; Van Gent et al., 2007).

\section{REFERENCES}

Allsop, N.W.H. and S.S.L. Hettiarachchi (1989). Wave reflections in harbours; the design, construction and performance of wave absorbing structures. Report OD 89, Hydraulics Research, Wallingford.

Andersen T. and H.F. Burcharth, 2004. CLASH Work package 4.4 D24 Report on additional tests. Part D Berm breakwater tests.

Andersen, T. L., 2006. Hydraulic Response of Rubble Mound Breakwaters : Scale Effects - Berm Breakwaters. Aalborg University, Dept. of Civil Eng., PhD thesis, $429 \mathrm{pp}$. http://vbn.aau.dk/fbspretrieve/6044235/Hydraulic_Response_of_Rubble_Mound_Breakwaters.

Battjes, J.A., 1974. Surf similarity. Proc. 14th Conf. on Coastal Eng., ASCE, 466-480.

Bruce, T., Van der Meer, J. W., Franco, L. and J. Pearson, 2006. A comparison of overtopping performance of different rubble mound breakwater armour. Proc. XXX ICCE, San Diego, vol. $5,4567-4579$.

Cappietti, L., Clementi, E., Aminti, P. and A. Lamberti, 2006. Piling-up and filtration at low crested breakwaters of different permeability. Proc. XXX ICCE, San Diego, vol. 5, 4957-4969.

Davidson, M. A., Bird, P.A.D., Bullock, G.N. and D.A. Huntley, 1996 A new non-dimensional number for the analysis of wave reflection from rubble mound breakwaters, Coastal Eng., 28, 93- 120.

EurOtop Manual, 2007. Latest version downloadable from: http://www.overtopping-manual.com.

Garcia N., Lara J.L., Losada I.J., 2004. 2-D numerical analysis of near-field flow at low-crested breakwaters, Coastal Engineering, 51 (10-11), 991-1020. 
Lissev, N. 1993. Influence of the core configuration on the stability of berm breakwaters. Experimental model investigations. Report No. R-6-93, Department of Structural Engineering, University of Trondheim, The Norwegian Institute of Technology.

Losada, M.A. and Giménez-Curto, L.A., 1981. Flow characteristics on rough, permeable slopes under wave action. Coastal Eng., 4, 187-206.

Miche, M., 1951. Le pouvoir reflêchissant des ouvrages maritimes exposés à l'action de la houle. Ann. Ponts Chausées, 121, 285-319.

Numata, A., 1976. Laboratory formulation for transmission and reflection at a permeable breakwater of artificial blocks. Coastal Eng. Jpn., XIX: 47-58.

Panizzo, A. and R. Briganti, 2007. Analysis of wave transmission behind low-crested breakwaters using neural networks, Coastal Eng., in press, doi:10.1016/j.coastaleng.2007.01.001 .

Postma, G. M., 1989. Wave reflection from rock slopes under random wave attacks, $\mathrm{PhD}$ thesis, Delft University of Technology.

Seelig W.N. \& J.P. Ahrens, 1981. Estimation of wave reflection and energy dissipation coefficients for beaches, revetments and breakwaters. CERC Tech. paper 81-1, USACE, Vicksburg, MS.

Steendam, G. J., Van der Meer, J. W., Verhaeghe, H., Besley, P., Franco, L. and M. van Gent, 2004. The international database on wave overtopping, Proc. ICCE 2004, 4301-4313.

TAW, 2002. Wave run-up and wave overtopping at dikes. Author: J.W. van der Meer. Technical Report of the Technical Advisory Committee on Water Defences in the Netherlands.

Ursell, J.N., Dean, R.G. and Yu, Y.S., 1960. Forced small amplitude water waves: A comparison of theory and experiment. J. Fluid Mech., 7(1): 33-52.

Van der Meer, J.W., 1992. Conceptual design of rubble mound breakwaters. Proc. of a short course on the design and reliability of coastal structures, attached to 23rd Conf. Coastal Eng., Venice. Tecnoprint, 447-510.

Van der Meer, J.W., Briganti, R., Zanuttigh, B. and B. Wang, 2005. Wave transmission and reflection at low crested structures: design formulae, oblique wave attack and spectral change, Coastal Eng., 52 (10-11), 915-929.

Van Gent, M., van den Boogaarda, H. F.P., Pozueta B. and J. R. Medina, 2007. Neural network modelling of wave overtopping at coastal structures, Coastal Eng., in press, doi:10.1016/j.coastaleng.2006.12.001.

Wang, B., Van der Meer, J.W., Otta, A. K., Chadwick, A. J. and J. Horrillo-Caraballo, 2005. Reflection of obliquely incident waves at low-crested structures, Proc. Coastal Dynamics'05.

Zanuttigh B. and J.W. van der Meer, 2006. Wave reflection from coastal structures. Proc. ICCE 2006, San Diego, vol. 5, 4337-4349 
KEYWORDS - COASTAL STRUCTURES 2007

WAVE REFLECTION FROM COMPOSITE SLOPES

Barbara Zanuttigh, Jentsje W. van der Meer

Abstract 53

Paper 25

Wave reflection

Coastal structures

Reflection coefficient

Berm

Database 